\title{
ERRATUM
}

\section{Fluorophore-assisted electrophoresis of urinary carbohydrates for the identification of patients with oligosaccharidosis- and mucopolysaccharidosis-type lysosomal storage diseases}

Christopher M. Starr, John C. Klock, Elisa Skop, Irene Masada and Tullio Giudici

On pages 170-173, the reproduction quality of the figures is poor. The figures are reprinted below and overleaf.
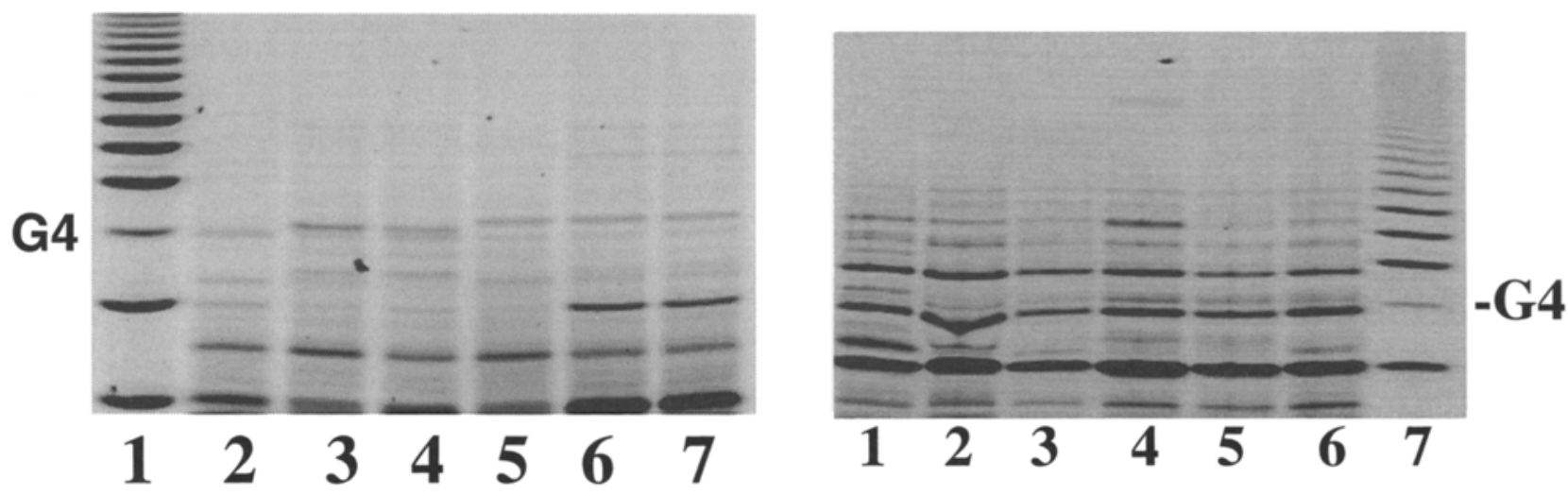

Figure 2.

Figure 4.
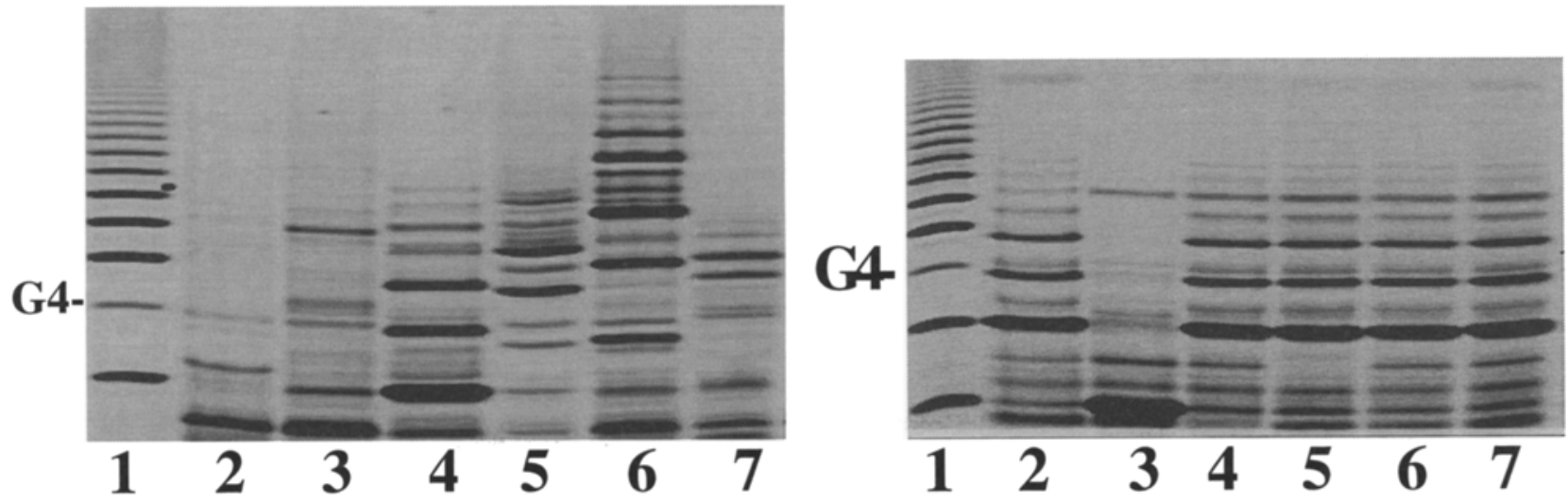

Figure 3.

Figure 5. 


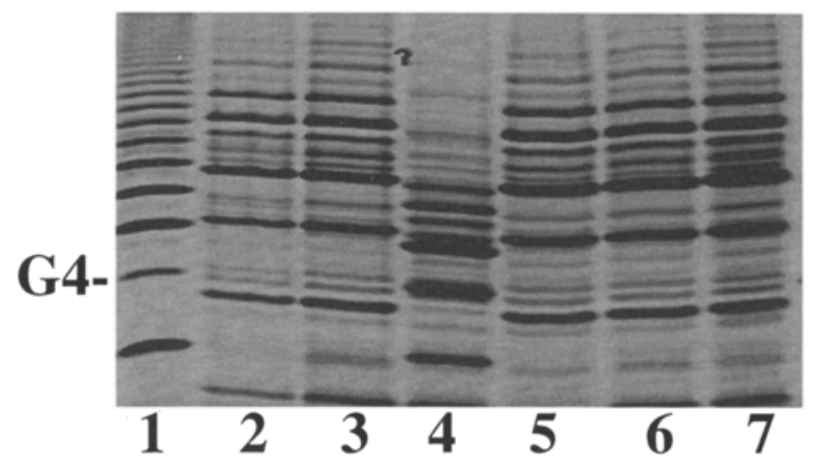

Figure 6.

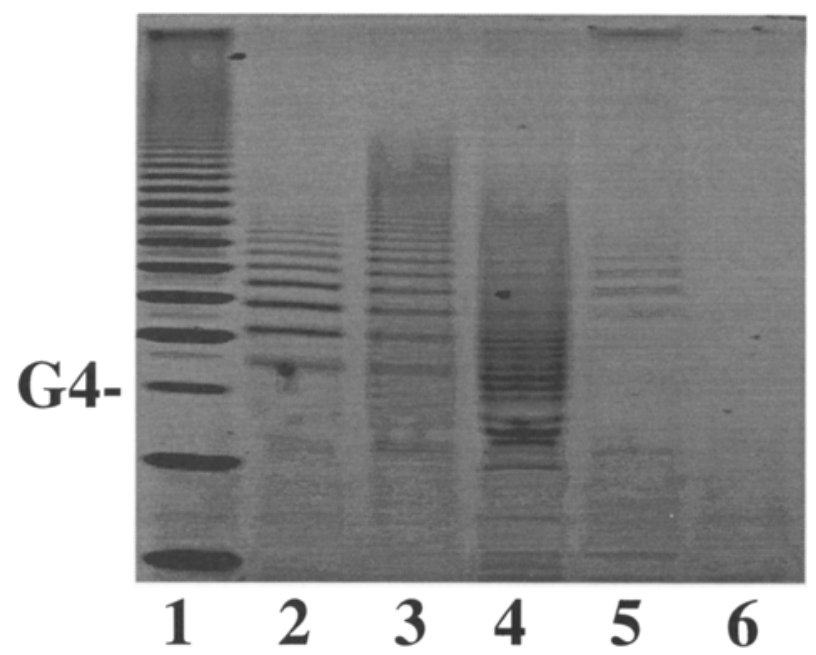

Figure 7.

The publishers apologise for this error.

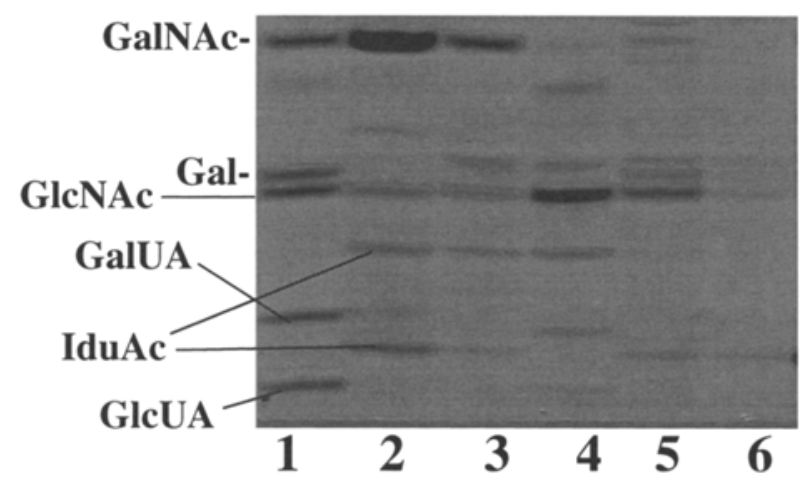

Figure 8. 